\title{
QUALIDADE DA ÁGUA EM MICROBACIAS HIDROGRÁFICAS COM AGRICULTURA NOS MUNICÍPIOS DE SANTARÉM E BELTERRA, PARÁ ${ }^{1}$
}

\author{
Christiane Patrícia Oliveira de Aguiar ${ }^{2}$, José Reinaldo Pacheco Peleja ${ }^{3}$ e Keid Nolan Silva Sousa ${ }^{4}$
}

\begin{abstract}
RESUMO - A expansão da fronteira agrícola no Oeste do Pará nas últimas décadas tem alterado a paisagem, antes ocupada por florestas ou agricultura familiar, provocando alterações ambientais com impacto nos recursos hídricos. O trabalho avaliou a qualidade da água de 24 microbacias hidrográficas, sob diferentes usos de solo: área natural/referência (Flona Tapajós), agricultura tradicional (PA-Moju) e agriculturas mecanizadas recentes e antigas de soja (Rodovias Curuá-Una e BR-163, respectivamente), com base na Resolução Conama n ${ }^{\circ} 357 / 05$, em Santarém e Belterra, no Pará. As coletas ocorreram em outubro/11 e abril/12. Parâmetros analisados: $\mathrm{pH}$, cor, turbidez, TDS, OD, DBO, nitrato, nitrito, nitrogênio amoniacal, fósforo total, clorofila-a e coliformes termotolerantes. Confrontando os resultados com os da Resolução, constatou-se no período seco que seis microbacias da Flona Tapajós e uma do PA-Moju apresentaram concentrações abaixo dos limites permissíveis para OD. Apenas uma microbacia (BR-163) apresentou pH no intervalo aceitável, e todas as microbacias do PA-Moju superaram o limite estabelecido para clorofila-a. A cor apresentou desconformidade em quatro microbacias da Curuá-Una, durante o período chuvoso. As atividades antrópicas estão causando assoreamento e aporte de compostos e nutrientes aos recursos hídricos, promovendo a sua degradação. A Resolução $n^{\circ}$ 357/05 necessita de adequações para a região Amazônica, visto que alguns parâmetros que apresentaram valores em desconformidade com a legislação refletem condições naturais da região.
\end{abstract}

Palavras-chave: Recursos hídricos; Uso do solo; Limnologia.

\section{WATER QUALITY IN MICRO WATERSHEDS WITH AGRICULTURE IN THE MUNICIPALITIES OF SANTARÉM AND BELTERRA, PARÁ}

\begin{abstract}
The expansion of the agricultural frontier in the west of Pará in recent decades has changed the landscape once occupied by family agriculture or forests, causing environmental changes impacting on water resources. The study evaluated the quality of water of 24 micro watersheds under different land uses: natural/reference area (Flona Tapajós), traditional agriculture (PA - Moju) and recent mechanized farming and old soybean crops (Highways Curuá-Una and BR-163, respectively), based on Conama Resolution $n^{\circ} 357 / 05$, in Santarém and Belterra (PA). The samples were collected in October/11 and April/12. Analyzed parameters: pH, color, turbidity, TDS, DO, BOD, nitrate, nitrite, ammonia nitrogen, total phosphorus, chlorophyll-a and fecal coliform. Comparing the results to the resolution, it was found that in the dry period six micro watersheds from Flona Tapajós and one from PA-Moju had concentrations below the permissible limits for DO. Only one micro watershed (BR-163) showed $p H$ within the acceptable range, and all the micro watersheds from $P A-M o j u$ exceeded the limit for chlorophyll-a. The color showed inconsistency in four micro watersheds of Curuá-Una, during the rainy season. Human activities are causing siltation and supply of compounds and
\end{abstract}

\footnotetext{
${ }^{1}$ Recebido em 23.05.2014 aceito para publicação em 02.10.2014.

${ }^{2}$ Universidade Federal do Oeste do Pará - UFOPA, Instituto de Ciências e Tecnologia das Águas - ICTA, Santarém, PA

- Brasil. E-mail: <christianedeaguiar@hotmail.com>.

${ }^{3}$ Universidade Federal do Oeste do Pará - UFOPA, Instituto de Ciências e Tecnologia das Águas - ICTA, Santarém, PA

-Brasil.E-mail: <reinaldopeleja@yahoo.com.br>.

${ }^{4}$ Universidade Federal do Oeste do Pará - UFOPA, Instituto de Ciências e Tecnologia das Águas - ICTA, Santarém, PA, Brasil.E-mail: <keid@ufpa.br>.
} 
nutrients to water resources, promoting their degradation. Resolution $n^{\circ} 357 / 05$ needs to be adjusted for the Amazon region, since some parameters that presented values in violation of the law reflect natural conditions of the region.

Keywords: Water resources; Land use; Limnology.

\section{INTRODUÇÃO}

O crescimento demográfico e a intensificação das atividades agropecuária e industrial têm aumentado a demanda por água no planeta (SETTI et al., 2000). Segundo Barros (2006), a expansão da fronteira agrícola provocou o aumento considerável no consumo de recursos hídricos, em especial para as atividades de irrigação.

Apesar de não ser a única atividade a degradar a qualidade dos recursos hídricos, a aplicação de defensivos agrícolas, pesticidas, herbicidas, fertilizantes e de derivados residuais da criação intensiva de animais colabora, direta ou indiretamente, para a poluição dos corpos d'água, inclusive sem a rega, pois são transportados aos reservatórios superficiais ou subterrâneos por escoamento, causando poluição, eutrofização e redução do oxigênio disponível no meio aquático (RESENDE, 2002; INSTITUTO DA ÁGUA, 2003; LUCAS, 2010).

A expansão da agricultura mecanizada nos Municípios de Santarém e Belterra, PA, tem promovido diversos impactos ambientais como desmatamento, incluindo a destruição das matas ciliares, principalmente provocadas por queimadas, construção de barragens, desvio de cursos d'água e assoreamento de mananciais, que abastecem as comunidades locais para diversos usos (GREENPEACE, 2009; LEMOS et al., 2010). Aliado a isso, a aplicação de insumos destinados à fertilização do solo e proteção contra pragas e doenças nas culturas têm ocasionado alterações quantitativas e qualitativas nas águas superficiais, surgimento de doenças, conflitos sociais, oriundos da grilagem e expulsão das populações tradicionais, assim como a mortalidade de espécies aquáticas, em especial de peixes (NEPSTAD et al., 2001; LEMOS et al., 2010), base da alimentação paraense. Nesse contexto, a disponibilidade de água para a sobrevivência da espécie humana e da biosfera vem sendo comprometida, seja pela sua diminuição, seja pela possibilidade de contaminação provocada pelo uso de produtos químicos ou despejo de efluentes no meio ambiente (SETTI et al., 2000).
Considerando que tal recurso é essencial e apenas $2,5 \%$ do total de água do globo terrestre é considerada própria para o consumo e que, deste, menos de $0,01 \%$ está acessível ao homem, em forma de rios e lagos, é importante a sua proteção e prevenção contra atividades que possam causar a sua degradação (TUNDISI, 2003).

A Resolução n ${ }^{\circ}$ 357, do Conselho Nacional do Meio Ambiente (Conama), de 17 de março de 2005, define a classificação dos corpos d'água, sendo utilizada na avaliação da qualidade das águas brasileiras para os diversos usos, subsidiando o monitoramento da contaminação das águas superficiais (BRASIL, 2005).

Assim, este trabalho teve como objetivo investigar o efeito da agricultura tradicional e mecanizada sobre a qualidade das águas de microbacias hidrográficas, localizadas na área de influência da Rodovia BR-163 nos Municípios de Santarém e Belterra, no Estado do Pará, com ênfase nos aspectos limnológicos e com base na Resolução Conama n 357/05, de forma a fazer a comparação de qualidade da água dos igarapés que drenam bacias em quatro ambientes: os cultivos mecanizados antigos e recentes de soja (com média de 10 anos de uso do solo), com igarapés naturais (unidades de conservação) e igarapés situados em áreas de cultivo tradicional da região, considerando o efeito do período de chuvas e de estiagem local.

\section{MATERIAL E MÉTODOS}

\subsection{Caracterização da área de estudo}

Os Municípios de Santarém e Belterra estão localizados no Oeste paraense e cruzam a área de influência da Rodovia BR-163. Inseridos no bioma amazônico, apresentam densa floresta ombrófila e diversificação no relevo, com regiões de planalto a várzea ao longo do rio Amazonas. Os solos, em grande parte, possuem baixa fertilidade e elevados níveis de acidez (BRASIL, 2006).

O clima predominante é quente e úmido, com temperatura média anual oscilando entre $25^{\circ}$ e $27^{\circ} \mathrm{C}$. A umidade relativa média do ar varia entre 80 e $90 \%$, 
e a precipitação pluvial anual oscila entre 1.800 e 2.800 mm, com alternância de chuvas abundantes, no período de janeiro a julho, e curtos períodos de estiagem entre os meses de agosto a dezembro (EMBRAPA, 2014).

Os corpos d'água da região ainda não foram enquadrados pela Agência Nacional de Águas (ANA).

\subsection{Amostragem}

Vinte e quatro igarapés foram selecionados ao longo da área de influência da BR-163, entre os Municípios de Santarém e Belterra, distribuídos em quatro grupos: área natural de referência (Região da Floresta Nacional do Tapajós/Flona Tapajós); de cultivo mecanizado recente de soja (Região da Rodovia Curuá-Una); de cultivo mecanizado antigo de soja (Região da Rodovia BR163) e cultivo familiar tradicional (Região do Assentamento Moju/PA-Moju), com tempo de ocupação de uso do solo de 10, 15 e 16 anos, nas três últimas (Figura 1). Cada grupo foi composto por seis igarapés. Devido à presença de barragens interceptando igarapés da Rodovia BR-163, três desses tiveram amostras coletadas a montante e a jusante daquelas.

Fonte: Adaptado COOPVAG, 2009.

Source: Adapted from COOPVAG, 2009.

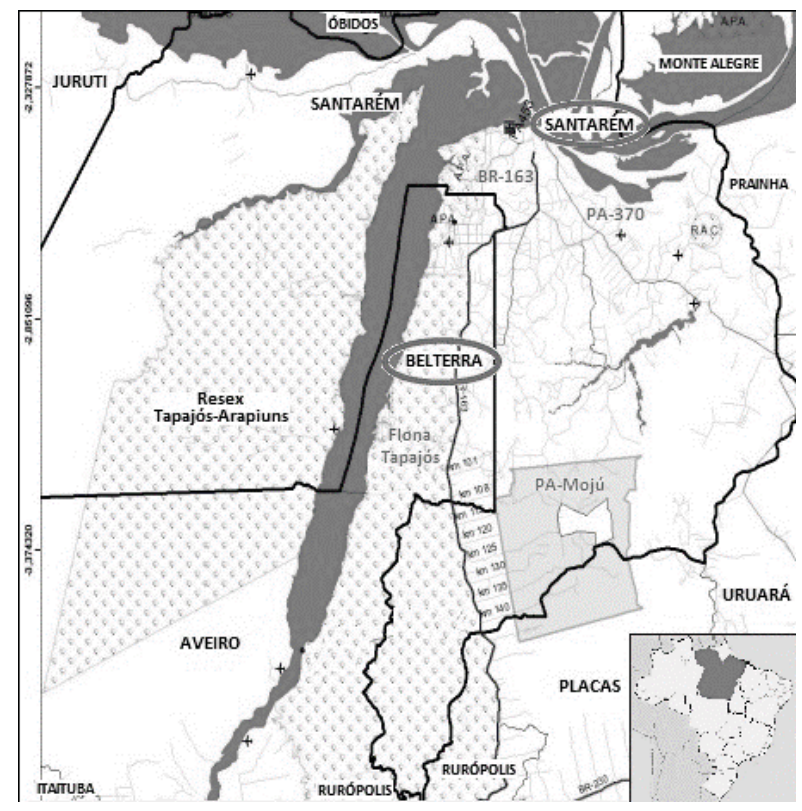

Figura 1 - Área de influência da Rodovia BR-163 e localização da área de estudo.

Figure 1 - Area of influence of the BR-163 highway and location of the study area.

\subsection{Coleta das amostras}

A coleta dos pontos de amostragem foi realizada nos meses de outubro de 2011 e abril de 2012. O primeiro mês representou o período de menor precipitação pluviométrica (período de estiagem) e o segundo, o de maior (período chuvoso). A metodologia para a coleta das amostras seguiu o protocolo analítico da Normatização Técnica NBR9897 (ABNT, 1987a), enquanto a conservação das amostras seguiu a NBR9898 (ABNT, 1987b).

As amostras foram coletadas na superfície do canal, no sentido inverso ao fluxo e armazenadas em frascos de polietileno, sendo três de $1.000 \mathrm{~mL}$ para as análises físico-químicas e um estéril de $250 \mathrm{~mL}$ para as análises microbiológicas. Os frascos foram conservados em caixas isotérmicas sob refrigeração e transportados ao Laboratório de Biologia Ambiental (LBA) da Universidade Federal do Oeste do Pará (UFOPA), para a realização das análises.

\subsection{Análise das amostras}

Doze parâmetros foram investigados: sólidos totais dissolvidos (TDS), oxigênio dissolvido (OD), potencial hidrogeniônico $(\mathrm{pH})$, coliformes termotolerantes $(\mathrm{CT})$, cor, clorofila-a (CL-a), demanda bioquímica de oxigênio (DBO), fósforo total (PT), nitrato $\left(\mathrm{NO}_{3}^{-}\right)$, nitrito $\left(\mathrm{NO}_{2}^{-}\right)$, nitrogênio amoniacal $\left(\mathrm{NH}_{3}\right)$ e turbidez $(\mathrm{Tu})$.

Os resultados das análises foram confrontados com os valores da Resolução Conama n 357/05, considerando-se as diferentes áreas de estudo e o período de coleta. Os parâmetros TDS, OD e pH foram determinados in loco, nos pontos de amostragem, antes do procedimento de coleta das amostras, com o auxílio de equipamentos portáteis das marcas Corning (TDS e OD) e Oakton (pH). Os demais parâmetros (coliformes termotolerantes, cor, clorofila-a, DBO, fósforo total, nitrato, nitrito, nitrogênio amoniacal e turbidez) foram determinados em laboratório, segundo as normas da APHA (2005), de acordo com a Tabela 1.

\subsection{Análise estatística}

Com base nos dados gerados e definidos pela Resolução Conama n 357/05 (BRASIL, 2005), foi realizado o diagnóstico da qualidade ambiental da área de estudo, dando ênfase à identificação das áreas de risco potencial a fenômenos erosivos e de assoreamento, de destituição da mata ciliar e de

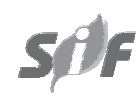

Revista Árvore, Viçosa-MG, v.38, n.6, p.983-992, 2014 
Tabela 1 - Parâmetros medidos em laboratório, unidade e métodos de análise empregados.

Table 1 - Parameters measured in laboratory, unit and methods of analysis employed.

\begin{tabular}{|c|c|c|}
\hline Parâmetro & Unidade & Método/Código Standard Methods (2005)* \\
\hline Coliformes termotolerantes & $\mathrm{UFC}^{1} .100 \mathrm{~mL}$ & Membrana filtrante - Meio Endo/Cód.: 9222-D \\
\hline Cor & mg. $L^{-1}$ & Platinum-cobalto/ Cód.: 2120-C \\
\hline Clorofila-a & $\mu \mathrm{g} \cdot \mathrm{L}^{-1}$ & Tricromático, acetona 90\%/ Cód.: 10200-H \\
\hline $\mathrm{DBO}$ & $\mathrm{mg} . \mathrm{L}^{-1}$ & Incubação/Eletrodo de membrana/5210-B \\
\hline Fósforo total & $\mu \mathrm{g} \cdot \mathrm{L}^{-1}$ & Redução com ácido ascórbico/ Cód.: 4500-PE \\
\hline Nitrato & mg. $L^{-1}$ & $\mathrm{~N}-\left(1-\right.$ naftyl)-etilenodiamina/ Cód.: $4500-\mathrm{NO}_{3}{ }^{-} \mathrm{C}$ \\
\hline Nitrito & $\mathrm{mg} \cdot \mathrm{L}^{-1}$ & N-(1-naftyl)-etilenodiamina/ Cód.: 4500- $\mathrm{NO}_{2}^{-} \mathrm{B}$ \\
\hline Nitrogênio amoniacal & $\mathrm{mg} \cdot \mathrm{L}^{-1}$ & $\mathrm{~N}$-(1-naftyl)-etilenodiamina/ Cód.: 4500- $\mathrm{NH}_{3} \mathrm{~F}$ \\
\hline Turbidez & $\mathrm{UNT}^{2}$ & Nefelométrico/ Cód.: 2130-B \\
\hline
\end{tabular}

* FONTE: American Public Health Association - APHA, 2005.

$1 \mathrm{UFC}=$ Unidade Formadora de Colônia/100 mL de amostra; e 2UNT = Unidade Nefelométrica deTurbidez

* SOURCE: American Public Health Association - APHA, 2005.

$1 C F U=$ Colony-Forming Unit $/ 100 \mathrm{~mL}$ of sample; and $2 U N T=$ Nephelometric Turbidity Unit.

contaminação por produtos químicos provenientes da sojicultura, em áreas de drenagem das microbacias hidrográficas. De modo geral, foi utilizada a estatística descritiva, para a apresentação dos resultados.

\section{RESULTADOS}

A definição do enquadramento de classe da água, segundo a Resolução n 357/05 (BRASIL, 2005), é ponto de partida para análise e discussão dos resultados da pesquisa. Os corpos d'água em estudo ainda não foram enquadrados em classes de qualidade pelo órgão ambiental competente; assim, segundo a legislação, corpos d'água nessa situação devem ser considerados como de classe 2 , em face dos usos preponderantes e de recreação de contato primário. Os resultados das análises estão apresentados nas Tabelas 2 e 3.

Considerando os resultados apresentados nas Tabelas 2 e 3 , de forma geral os valores de $\mathrm{pH}$ apresentaram-se ácidos, abaixo da faixa estabelecida pela legislação, com medianas de 4,9 a 5,6, durante a estação seca, enquanto, para a estação chuvosa, os valores oscilaram entre 4,9 e 5,4. Um igarapé da BR-163 foi a exceção, apresentando resultado dentro da normalidade das águas da classe $2(\mathrm{pH}=6,2)$, que estabelece valores entre 6,0 e 9,0. Os igarapés situados na unidade de conservação (Flona Tapajós) e de agricultura familiar apresentaram os menores valores de $\mathrm{pH}$ durante os períodos de coleta (medianas de 4,9 e 5,4, respectivamente). Observou-se no período chuvoso um gradiente decrescente nos valores de $\mathrm{pH}$.

A maioria das microbacias apresentou teores de OD normais para os dois períodos de análise, com maiores valores registrados durante a estação das chuvas $(5,1$

Revista Árvore, Viçosa-MG, v.38, n.6, p.983-992, 2014 a 9,1 mg/L-1) em relação ao período de estiagem $(2,1$ a $\left.8,6 \mathrm{mg} / \mathrm{L}^{-1}\right)$. Todos os pontos da área de referência (Flona Tapajós) e um ponto do Projeto de Assentamento Moju demonstraram, no período seco, valores abaixo do limite mínimo estabelecido $(<5 \mathrm{mg} / \mathrm{L})$, mas que se restabeleceram durante a estação chuvosa.

A DBO apresentou, na maioria dos igarapés estudados, valores inversos ao OD, com menores concentrações (mediana de $0,2 \mathrm{mg} . \mathrm{L}^{-1}$ ) registradas durante a estação chuvosa, à exceção da Flona Tapajós (1,0 a 4,5 mg.L. $\mathrm{L}^{-1}$ ). Não se observou comprometimento dos níveis de oxigênio dissolvido na água pela quantidade de matéria orgânica no período estudado, tanto nas áreas de cultivo quanto na área de conservação.

A concentração de clorofila-a foi maior durante o período seco, superando o limite estabelecido pela Resolução Conama, de $10 \mu \mathrm{g} . \mathrm{L}^{-1}$, em todos os pontos amostrados para a região de agricultura tradicional familiar (mediana de 19,42 $\mu \mathrm{g} . \mathrm{L}^{-1}$ ), havendo diminuição na estação de chuvas (mediana de 1,06 $\mu \mathrm{g}$.L $\mathrm{L}^{-1}$ ), à exceção do ponto PM03 (ACTAAIA 03), onde se registraram $28,57 \mu \mathrm{g} . \mathrm{L}^{-1}$.

Em relação à cor verdadeira da água dos igarapés, os teores nas regiões de estudo não foram homogêneos durante as estações. Quatro igarapés da área de cultivo recente de soja (Curuá-Una) apresentaram valores que ultrapassaram o máximo de $75 \mathrm{mg} . \mathrm{L}^{-1}$ da Resolução Conama, durante a estação das chuvas.

Os valores de turbidez ( 2 a 43 UNT), fósforo total $\left(2,1\right.$ a $\left.15,0 \mu \mathrm{g} . \mathrm{L}^{-1}\right)$ e nitrogênio amoniacal $(0,01$ a 1,42 $\left.\mathrm{mg} . \mathrm{L}^{-1}\right)$ variaram temporalmente, para os ambientes estudados, porém com extremos em conformidade com 


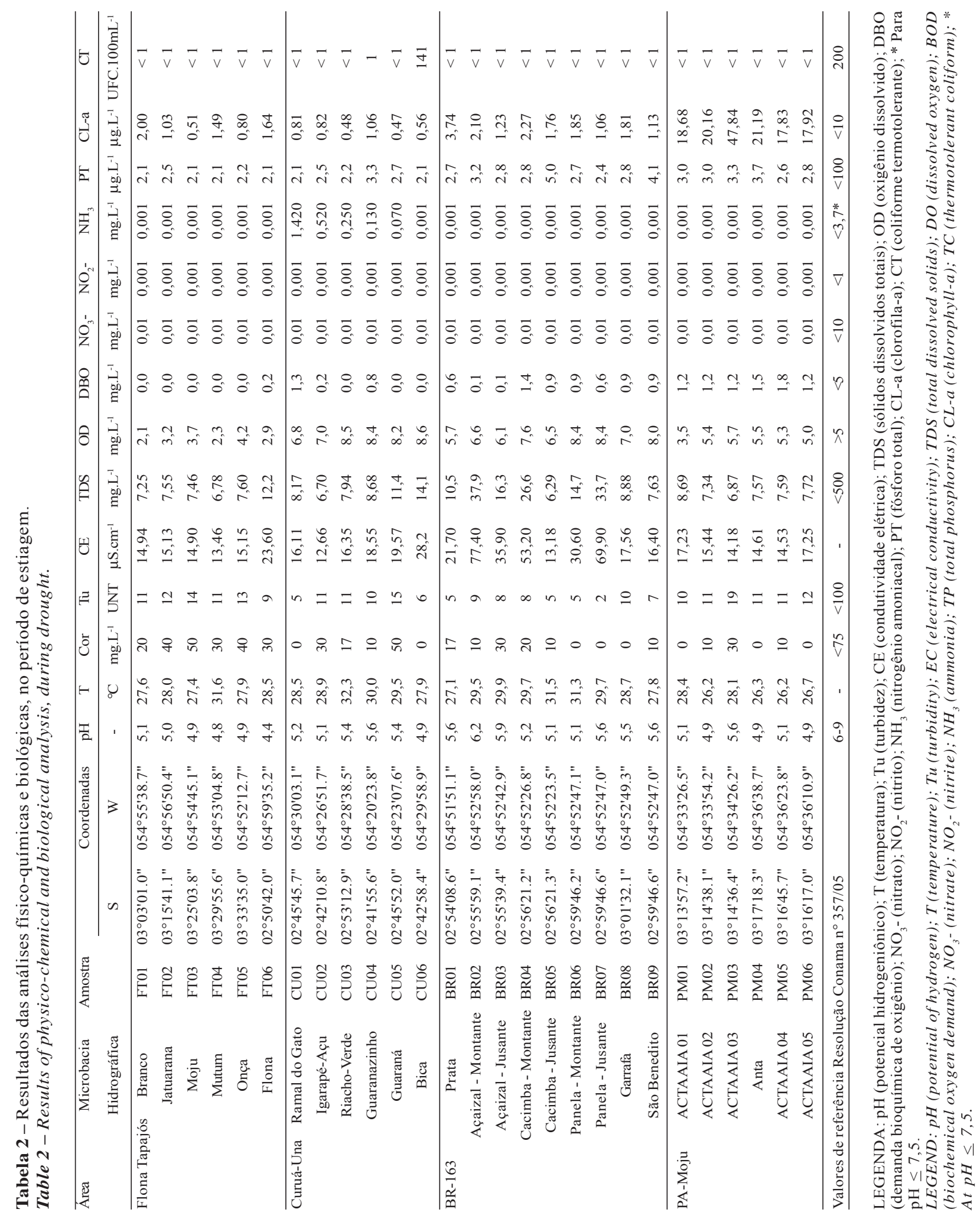




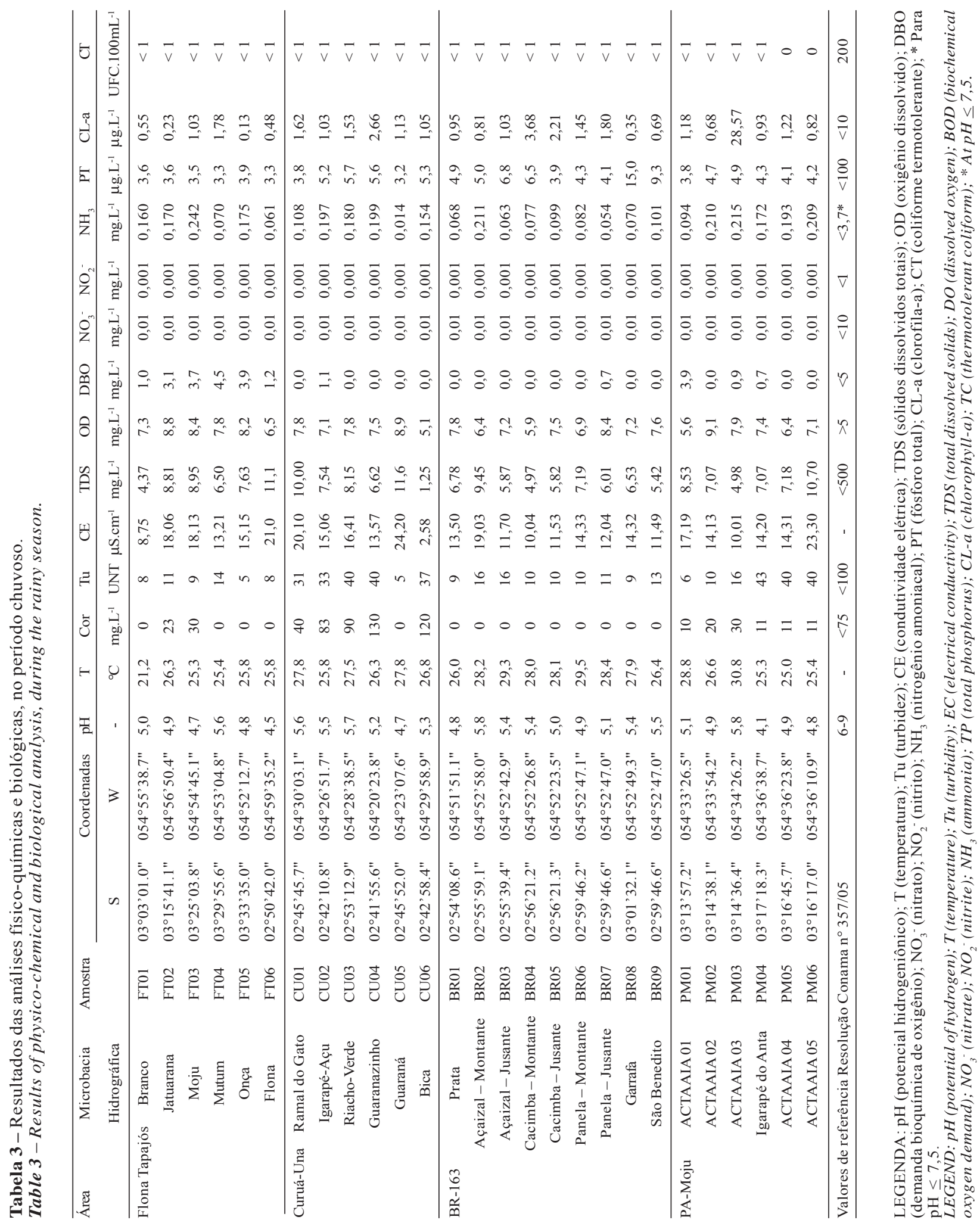

Revista Árvore, Viçosa-MG, v.38, n.6, p.983-992, 2014 
à legislação ambiental. Em relação à sazonalidade, as regiões antropizadas (agricultura) apresentaram maiores medianas dos parâmetros fósforo total $\left(4,9 \mu \mathrm{g} . \mathrm{L}^{-1}\right)$, nitrogênio amoniacal $\left(0,108 \mathrm{mg} . \mathrm{L}^{-1}\right)$ e turbidez (16 UNT) durante a estação chuvosa, em relação às medianas de 2,8 $\mu$ g.L. ${ }^{-1}, 0,001$ mg.L ${ }^{-1}$ e 10 UNT, respectivamente, para a estação de estiagem. Na área natural, o comportamento foi semelhante, com concentrações medianas de 3,6 $\mu$ g.L.- ${ }^{-1}$ para o fósforo total e de $0,165 \mathrm{mg}$. $\mathrm{L}^{-1}$ para o nitrogênio amoniacal, em comparação com as medianas de $2,1 \mu \mathrm{g} . \mathrm{L}^{-1}$ e $0,001 \mathrm{mg} \cdot \mathrm{L}^{-1}$, respectivamente, para a estação seca. A turbidez foi exceção, demonstrando aumento durante a estação seca (12 UNT) em comparação com a estação chuvosa (9 UNT).

As microbacias das regiões com agricultura revelaram medianas mais elevadas no período chuvoso para os parâmetros turbidez (16 UNT) e fósforo total (4,90 $\left.\mu \mathrm{g} . \mathrm{L}^{-1}\right)$, enquanto na Floresta Nacional do Tapajós as medianas foram maiores no nitrogênio amoniacal $\left(0,165 \mathrm{mg} \cdot \mathrm{L}^{-1}\right)$. Entretanto, no período de estiagem o componente turbidez demonstrou-se mais elevado na área natural (12 UNT), enquanto o fósforo total manteve maiores medianas nas áreas agricultáveis $\left(2,80 \mu \mathrm{g} . \mathrm{L}^{-1}\right)$, e os níveis de nitrogênio amoniacal foram semelhantes nos dois ambientes.

Os valores de nitrato $\left(0,01 \mathrm{mg} . \mathrm{L}^{-1}\right)$, nitrito $(0,001$ mg. $\left.\mathrm{L}^{-1}\right)$ e coliformes termotolerantes ( $<1$ UFC a 141 UFC. $100 \mathrm{~mL}^{-1}$ ) demonstraram-se abaixo do valor máximo permitido por lei e não variaram significativamente ao longo dos pontos de amostragem. Quanto ao aspecto bacteriológico, apenas os igarapés Guaranazinho (CU04) e Bica (CU06), do ambiente de cultivo mecanizado recente (Curuá-Una), revelaram indicador de contaminação fecal, durante o período de estiagem.

\section{DISCUSSÃO}

A Amazônia apresenta peculiaridades próprias em sua rede hidrográfica, influenciada particularmente pela floresta e clima. As águas da região possuem características ácidas, em virtude da contribuição da área da bacia hidrográfica e da decomposição de material orgânico do ambiente em compostos ácidos, responsáveis pelos baixos valores de $\mathrm{pH}$ encontrados também nos solos (SIOLI, 1976; SIQUEIRA et al., 2012). Portanto, em relação ao $\mathrm{pH}$, as águas estariam em desconformidade com a legislação vigente, considerando-se a Resolução Conama $\mathrm{n}^{\circ} 357 / 05$, contudo os valores refletem condições naturais da região.
Fatores físicos, químicos e bioquímicos influenciam os teores de oxigênio dissolvido (OD) em águas naturais (APHA, 2005). Assim, maiores teores de OD foram observadas no período chuvoso, em razão do aumento da cota, que elevou a velocidade do fluxo da água e a oxigenação nos sistemas fluviais.

Em relação à demanda bioquímica de oxigênio (DBO), apesar dos menores resultados apresentados durante a estação chuvosa, não foi observado comprometimento dos níveis de oxigênio dissolvido na água pela quantidade de matéria orgânica no período estudado, tanto nas áreas de cultivo quanto na área de conservação. Valores superiores de DBO foram encontrados por Lemos (2003), em áreas com uso de solo destinadas principalmente a atividades agrícolas, porém ainda dentro dos valores determinados pela Resolução Conama n ${ }^{\circ}$ 357/05.

As maiores concentrações de clorofila-a registradas durante o período seco deveram-se ao desenvolvimento de algas e macrófitas aquáticas. A região de agricultura tradicional familiar (PA-Moju) apresentou valores que superaram o limite estabelecido pela Resolução Conama. A retirada da mata ciliar deve ter contribuído para a sedimentação durante o período chuvoso e para a maior exposição do espelho d'água à luz solar no período de estiagem.

No rio Arari, localizado na Ilha de Marajó (PA), com áreas de fazenda e lavoura, Alves e colaboradores (2012) demonstraram valores de clorofila-a maiores no período de chuvas quando comparados ao período seco, com concentrações oscilando de 4.220 a 38.320 $\mu \mathrm{g} . \mathrm{L}^{-1}$ no período chuvoso e de 3.900 a $25.810 \mu \mathrm{g} . \mathrm{L}^{-1}$, no período seco.

As áreas da Flona Tapajós (Unidade de Conservação) e BR-163 (cultivo mecanizado antigo de soja) apresentaram redução nas concentrações da cor verdadeira, durante o período chuvoso. Esse comportamento se deve, provavelmente, à diluição das partículas coloidais ou em suspensão nos corpos d'água. Entretanto, nas áreas do assentamento PA-Moju (agricultura familiar) e PA-370 (cultivo mecanizado recente de soja), houve elevação nos níveis do parâmetro, que pode estar relacionada ao contato da água com materiais orgânicos em decomposição ou pelo carreamento de compostos durante o deflúvio, oriundos do aumento da lixiviação do solo, provocado pela falta de proteção da vegetação ripária. Segundo Sioli (1976), a coloração 
adquirida pelos corpos d'água é resultado da lixiviação dos compostos resultantes da decomposição da vegetação pela água das chuvas ou do total de sólidos dissolvidos.

Considerando as quatro áreas de estudo, os valores de turbidez, nitrogênio amoniacal e fósforo total, enquadraram-se no recomendado pela Resolução Conama $n^{\circ} 357 / 05$. De maneira geral, os maiores níveis dos parâmetros ocorreram durante a estação de chuvas e nas áreas com agricultura.

Na microbacia de Ribeirão Marins (SP), utilizada para atividades de agricultura e pecuária, foram encontrados valores de turbidez entre 9 e 19 UNT, no período seco, e de 15 a 26 UNT, no período chuvoso, além de concentrações de amônia e nitrato que ultrapassaram os valores máximos preconizados pela norma atribuídos ao aporte dos nutrientes provenientes do processo erosivo do solo e de lixiviações (LUCAS et al., 2010). Na bacia hidrográfica de Chesapeake, Estados Unidos, o uso de um terço da área com atividade agrícola foi responsável por um aporte de $58 \%$ de fósforo no rio, relacionado ao escoamento superficial do nutriente (PIONKE et al., 2000).

Independentemente da sazonalidade, não foram detectadas perturbações em relação aos componentes nitrato, nitrito e coliformes termotolerantes, que se mantiveram dentro do limite recomendado pela Resolução $n^{\circ} 357 / 05$, do Conama, embora tenha se constatado processos de erosão do solo e de sedimentação nas áreas antropizadas.

A supressão da vegetação ciliar, o desmatamento de outras (ou grandes) áreas, assim como as queimadas, são práticas utilizadas nas atividades agropecuárias, que podem estar contribuindo para o assoreamento, aporte de compostos e nutrientes para as microbacias dos Municípios de Belterra e Santarém, na área de influência da BR-163.

\section{CONCLUSÃO}

Comparando os 12 parâmetros de qualidade com os padrões estabelecidos pela Resolução Conama $n^{\circ} 357 / 05$, constatou-se que os parâmetros $\mathrm{pH}$, oxigênio dissolvido, clorofila-a e cor estiveram em desacordo com essa Resolução, e as três primeiras predominaram no período de estiagem e a última, no período de chuvas.

Revista Árvore, Viçosa-MG, v.38, n.6, p.983-992, 2014
As alterações nos valores dos parâmetros limnológicos ocorreram em diferentes áreas geográficas, o pH para a área da agricultura mecanizada (BR-163 e Curuá-Una) e da agricultura tradicional (PA-Moju); oxigênio dissolvido, para a Floresta Nacional do Tapajós (Flona Tapajós); clorofila-a para as áreas de cultivo familiar tradicional (PA-Moju) e cor para a área de agricultura mecanizada recente (Curuá-Una).

A qualidade da água das microbacias da área de cultivo mecanizado recente mostrou-se mais sensível aos efeitos da estação chuvosa, principalmente para o parâmetro cor, sugerindo, dessa forma, relação com os processos de lixiviação e carreamento de sedimentos associados aos fenômenos de escoamento superficial e subsuperficial mais acentuados na área de drenagem dessas microbacias nesse período.

A precipitação, as características do solo, seus diferentes usos e o tamanho da área de drenagem são fatores importantes que podem estar contribuindo para alterações na qualidade da água das microbacias.

Considerando a Resolução no 357/05, do Conselho Nacional do Meio Ambiente - água doce classe 2, de maneira geral, todos os pontos estudados apresentaram alteração na qualidade da água, porém permanecem ainda em condições adequadas para os usos preponderantes.

A Resolução Conama ${ }^{\circ} 357 / 05$ necessita de adequações para a região Amazônica, visto que alguns parâmetros que apresentaram valores em desconformidade com a Resolução refletem condições naturais da região.

\section{AGRADECIMENTOS}

À Netherland Organization for Scientific Research/ Wotro Science for Global Development/Project Land and Rights in Troubled Waters, pelo apoio financeiro; e à Universidade Federal do Oeste do Pará/Instituto de Ciências e Tecnologia das Águas/Laboratório de Biologia Ambiental, por terem propiciado a realização deste trabalho.

\section{REFERÊNCIAS}

ALVES, I.C.C.; EL-ROBRINI, M.; SANTOS, M.L.S.; MONTEIRO, S.M.; BARBOSA, L.P.F.; GUIMARÃES, J.T.F. Qualidade das águas superficiais e avaliação do estado trófico do rio 
Arari (Ilha de Marajó, norte do Brasil). Acta Amazônica, v.42, n.1, p.115-124, 2012.

AMERICAN PUBLIC HEALTH ASSOCIATION APHA. Standard methods for the examination of water and wastewater. 21.ed. Washington: 2005.

\section{ASSOCIAÇÃO BRASILEIRA DE NORMAS} TÉCNICAS - ABNT. NBR 9897: Planejamento de amostragem de efluentes líquidos e corpos receptores. Rio de Janeiro: 1987a. 22p.

\section{ASSOCIAÇÃO BRASILEIRA DE NORMAS} TÉCNICAS - ABNT. NBR 9898: Planejamento de amostragem de efluentes líquidos e corpos receptores. Rio de Janeiro: 1987b. 14p.

\section{BARros, F. G. N. A Bacia Amazônica} Brasileira no contexto geopolítico da escassez mundial de água. 153f. 2006. Dissertação (Mestrado em Economia) Universidade da Amazônia, Pará, 2006.

BRASIL. Conselho Nacional do Meio Ambiente CONAMA. Resolução Conama $n^{\circ}$ 357, de 17 de março de 2005. Dispõe sobre a classificação dos corpos de água e diretrizes ambientais para o seu enquadramento, bem como estabelece as condições e padrões de lançamento de efluentes, e dá outras providências. (https:// www.mma.gov.br/conama). Acesso em: 10 de jan. 2012.

BRASIL. Presidência da República. Casa Civil. Plano de desenvolvimento regional sustentável para a área de influência da rodovia BR-163 Cuiabá-Santarém. Brasília: 2006. 193p. (Grupo de Trabalho Interministerial, Decreto de 15 de março de 2004).

\section{COOPERATIVADE PROFISSIONAIS LIBERAIS DO} VALE DO ARAGUAIA - COOPVAG/PDA. Plano de Desenvolvimento do Assentamento. Projeto de Assentamento Moju I e II. Instituto de Colonização e Reforma Agrária/SR-30. Conceição do Araguaia: 2009. 354p.

\section{EMPRESA BRASILEIRA DE PESQUISA}

AGROPECUÁRIA - EMBRAPA. Amazônia Oriental - Embrapa. Centro de Pesquisa Agropecuária do Trópico Úmido - CPATU. Caracterização da área de estudo. ZEE BR-163. Belém: 2014. Disponível em: $<$ http:// zeebr163.cpatu.embrapa.br/index.php>. Acesso em: 28 jul. 2014.

\section{GREENPEACE; SINDICATO DOS}

TRABALHADORES E TRABALHADORAS RURAIS DE SANTARÉM; PROJETO SAÚDE E ALEGRIA; SINDICATO DOS TRABALHADORES RURAIS DE BELTERRA. Mapeamento comunitário dos impactos da soja em Santarém e Belterra. Santarém: 2009. (http:/ /www.greenpeace.org/brasil/pt/Noticias/mapaparticipativo-inedito-exp/). Acesso em: 31 de maio 2011.

Instituto DA ÁGUA. A água, a terra e o homem - ciclo da água. 2003. 20p.

LEMOS, M.; FERREIRA NETO, M.; DIAS, N. S. Sazonalidade e variabilidade espacial da qualidade da água na Lagoa do Apodi, RN. Revista Brasileira de Engenharia Agrícola e Ambiental, v.14, n.2, p.155-164, 2010.

LEMOS, C. A. Qualidade da água de uma bacia hidrográfica inserida na Reserva da Biosfera da Mata Atlântica, Maquiné, Rio Grande do Sul, Brasil. 98f. 2003. Dissertação (Mestrado em Ecologia) - Instituto de Biociências, UFRGS, Porto Alegre, 2003.

LUCAS, A. A. T.; FOLEGATTI, M. V.; DUARTE, S. N. Qualidade da água de uma microbacia hidrográfica do rio Piracicaba, SP. Revista Brasileira de Engenharia Agrícola e Ambiental, v.14, n.9, p.937-943, 2010.

NEPSTAD, D.; CARVALHO, G.; BARROS, A.C.; ALENCAR, A.; CAPOBIANCO, J.P.; BISHOP, J.; MOUTINHO, P.; LEFEBVRE, P.; SILVA JR., U.L.; PRINS, E. Road paving, fire regime feedbacks, and the future of Amazon forests. Forest Ecology and Management, v.154, n.3, p.395-407, 2001.

PIONKE, H. B.; GBUREK, W.; SHARPLEY, A. N. Critical source area controls on water quality in an agricultural watershed located in de Chesapeake basin. Ecological Engineering, v.14, n.4, p.325-335, 2000.

RESENDE, A. V. Agricultura e qualidade da água: contaminação da água por nitrato. Planaltina. Brasília: Embrapa Cerrados, 2002. 29p.

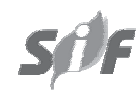

Revista Árvore, Viçosa-MG, v.38, n.6, p.983-992, 2014 
SETTI, A.A.; LIMA, J.E.F.W.; CHAVES, A.G.M.; PEREIRA, I.C. Introdução ao gerenciamento de recursos hídricos. 2.ed. Brasília: Agência Nacional de Energia Elétrica; Agência Nacional de Águas, 2000. 207p.

SIOLI, H. A limnologia na região amazônica brasileira. In: ENCONTRO NACIONAL SOBRE LIMNOLOGIA, PISCICULTURA E PESCA CONTINENTAL, 1., 1976, Belo Horizonte.
Anais... Belo Horizonte: 1976. p.153-169.

SIQUEIRA, G. W.; APRILE, F.; MIGUEIS, A. M. Diagnóstico da qualidade da água do rio Parauapebas (Pará - Brasil). Acta Amazônica [online], v.42, p.413-422, 2012.

TUNDISI, J. G. Ciclo hidrológico e gerenciamento integrado. Ciência e Cultura, v.55, n.4, p.3133, 2003. 